\title{
Figures and First Years: An Analysis of Calculus Students' Use of Figures in Technical Reports
}

\author{
Nathan J. Antonacci \\ Ithaca College, nathanjohn48@gmail.com \\ Michael Rogers \\ IthacaCollege,mrogers@ithaca.edu \\ Thomas J. Pfaff \\ Ithaca College, tpfaff@ithaca.edu \\ Jason G. Hamilton \\ Ithaca College, jhamilton@ithaca.edu
}

Follow this and additional works at: https://digitalcommons.usf.edu/numeracy

Part of the Other Mathematics Commons, and the Science and Mathematics Education Commons

\section{Recommended Citation}

Antonacci, Nathan J., Michael Rogers, Thomas J. Pfaff, and Jason G. Hamilton. "Figures and First Years: An Analysis of Calculus Students' Use of Figures in Technical Reports." Numeracy 10, Iss. 2 (2017): Article 10. DOI: http://doi.org/10.5038/1936-4660.10.2.10 


\title{
Figures and First Years: An Analysis of Calculus Students' Use of Figures in Technical Reports
}

\begin{abstract}
This three-year study focused on first-year Calculus I students and their abilities to incorporate figures in technical reports. In each year, these calculus students wrote a technical report as part of the Polar Bear Module, an educational unit developed for use in partner courses in biology, computer science, mathematics, and physics as part of the Multidisciplinary Sustainability Education (MSE) project at Ithaca College. In the first year of the project, students received basic technical report guidelines. In year two, the report guidelines changed to include explicit language on how to incorporate figures. In year three, a grading rubric was added to the materials provided to one of the two classes. In all three years, the students performed below expectations in their use of graphs in their reports. Reviews of the figures in the 78 technical reports written by the 106 students showed repeated deficiencies in the figures and how the students used them in the discussion sections and in evidence-based arguments. In year three the student's quantitative literacy (QL) skills were assessed using an extract from a QL assessment instrument published in Numeracy. The results indicated that the students could both read and interpret figures, suggesting that issues with QL were not the main contributor to student difficulty with written discussion about graphs. The study underscores the need that explicit instructional attention be given to developing student knowhow in the use of figures in technical reports.
\end{abstract}

\section{Keywords}

calculus, quantitative literacy, figures and graphs, technical report writing

\section{Creative Commons License}

\section{c) (7) (8)}

This work is licensed under a Creative Commons Attribution-Noncommercial 4.0 License

\section{Cover Page Footnote}

Nathan Antonacci holds a Bachelor's Degree in Physics from Ithaca College and spent three years as an undergraduate researcher in Prof. Rogers's education research group. He is currently employed at Rapid Response Monitoring in Syracuse, NY, as a Leadership Development Associate.

Jason Hamilton is Professor and Chair of Environmental Studies and Sciences at Ithaca College. He has a Ph.D. in Quantum Chemistry and a Ph.D. in Plant Ecophysiology, both from the UC - Santa Barbara. Current research interests include Sustainability Education, Non-Timber Forest Products and Forest Management, and developing the Science of Traditional Animal Tracking.

Michael "Bodhi" Rogers is Professor of Physics and Astronomy and Coordinator of Science Teaching at Ithaca College. He has a Ph.D. in Physics and a Masters in Archaeology, from Oregon State. Primary scholarly interests are Astronomy and Physics Education Research, Geophysical Archaeology, and Historic Preservation using 3D Laser Scanning.

Thomas J. Pfaff is Professor of Mathematics at Ithaca College. He has a Ph.D. in Mathematics and Masters in both Mathematics and Applied Statistics, all from Syracuse Univ., and a B.S. in Exercise Science. Current research interests include incorporating sustainability into the mathematics classrooms; he maintains a sustainability blog with curriculum material at http://sustainabilitymath.org/. 


\section{Introduction}

As traditional career paths become cross-disciplinary and new job opportunities emerge, educational institutions must provide students with the tools needed to address complex real-world problems. College graduates with skill sets spanning multiple disciplines, especially those in science, technology, engineering, and mathematics (STEM) fields, will be valuable to employers and more capable of devising solutions to problems that may not yet even exist. It is particularly important that students can convey information in written reports, which are used to convey knowledge.

We assigned a multi-disciplinary technical-writing project to first-year students in a Calculus 1 course at Ithaca College. ${ }^{1}$ We were surprised to find that many of the technical reports contained figures that were missing titles, captions, and axes labels. Some of the figures were not referred to or even mentioned in the actual text of the papers. As figures can be a focal point of a technical report, these omissions were concerning.

We decided to review the graphs in the technical reports to see if there were commonalities in the errors. We began to question student's ability to read and interpret figures. Since the problem with the use of figures was not anticipated, we chose to experiment over three years to attempt to get at the root cause of the problem. Graphs and tables are commonly used in textbooks and student assignments; having the ability to examine, comprehend, and then use those figures to answer questions, to solve problems, or both is a crucial part of quantitative literacy (QL).

This note builds upon an earlier study (Pfaff , Rogers et al. 2011). It seeks to answer the following question: Are students able to incorporate high-quality figures in technical reports in a Calculus 1 course where students are typically in their first year of higher-level education? If not, why aren't they?

The context of the use of figures in technical report writing arose from the Multi-disciplinary Sustainability Education (MSE) project at Ithaca College ${ }^{2}$ (Rogers et al. 2015). The MSE was implemented in courses in biology (Hamilton

\footnotetext{
${ }^{1}$ Ithaca College is a private regional university located in the Finger Lakes region of upstate New York. The college comprises five schools: Business, Communications, Health Science and Human Performance, Humanities and Sciences, and Music. The student body consists of approximately 6000 undergraduate and 500 graduate students. Ithaca College is a residential campus with $70 \%$ of the students living in college housing. There are over 150 waterfalls within a 10-square mile area surrounding Ithaca, and slightly over 30,000 residents, while only about 200 miles northwest of Manhattan.

${ }^{2}$ NSF DUE 0837721. See http://www.ithaca.edu/mse/. For Award Abstract \#0837721, see https://nsf.gov/awardsearch/showAward?AWD_ID=0837721\&HistoricalAwards=false
} 
et al. 2010), computer science (Erkan et al. 2010; Erkan et al. 2012), mathematics (Pfaff, Erkan et al. 2011; Pfaff, Rogers et al. 2011), and physics (Rogers et al. 2013) to expose students to the opportunity to tackle real-world issues and develop skill sets that employers desire. The project involved using a module: a theme-based instructional project guided by a question. Modules were designed to introduce students to $21^{\text {st }}$-century problems while teaching discipline-specific content. The MSE modules were also meant to increase student engagement with material.

The MSE modules, including the module used in the study, have five main goals:

- Continue solid discipline-specific learning.

- Develop understanding about the characteristics of $21^{\text {st }}$ - century problems, particularly those related to sustainability.

- Develop an understanding of how different disciplines can work together to understand complex problems.

- Develop an increased engagement in learning by tackling relevant problems.

- Create curriculum materials to meet these goals and develop implementation logistics that can also be used by other STEM and sustainability educators with a variety of course configurations.

The module that was used in the Calculus I course posed the following question: "What are the current and future impacts of global climate change on polar bears?” For obvious reasons, we called this module the Polar Bear Module. ${ }^{3}$ The module was structured so that each discipline could designate a course in which work completed in the course would be shared with the classes in the other disciplines. Each course involved with the module formed sub-questions, which addressed the main question of the module from their discipline-specific perspective. Students in the first-semester calculus course, for example, used data on global temperature averages and the extent of Arctic sea ice to create graphs with best-fitting curves. These graphs were used to address questions about rates of change, inflection points, and future trends, which then led to more questions about the future impact of the trends.

Calculus students wrote technical reports after analyzing the data. In a more traditional calculus course, data gathered might be used only to find a specific answer to a specific problem. If a professor asked students to locate an inflection point on a graph, for example, they would be finished with the work as soon as the point was located. With the Polar Bear Module, not only would students need

\footnotetext{
${ }^{3}$ See http://www.ithaca.edu/mse/modules2/ (Note, much of the material on the website is password protected. Directions are included there on how instructors can apply for a password.)
} 
to find the inflection point; they would have to explain in words why that point was significant, what its real-life implications were, and then compare that point to others on the graph. The module thus provided context for the students' work. No longer were the students finding answers just for the sake of obtaining a correct value; they were making connections between results and implications.

These technical reports in the Calculus 1 course were collected and graded by the instructor of the course using a detailed grading sheet. ${ }^{4}$ The reports were then sent to the classes in the other disciplines (with each student's permission) so that students in other courses could answer those questions from calculus students and further their own work. It was through the implementation of the Polar Bear Module that we first noticed the issue of student's use of figures.

\section{Methods}

Our results span three years of fall semester Calculus 1 classes that started as part of the MSE project. All of the calculus courses where taught by Pfaff; the MSE team was included on intervention decisions even though the grant award had officially ended by the third year of our results here. In each year, students had to write a technical report as part of the Polar Bear Module. In the first year, we simply provided basic technical report guidelines for the students (see appendix A). These student reports brought the issue of figures to our attention. In the second year, we changed the report guidelines to include explicit language on how to incorporate figures (see appendix B) in an attempt to improve the student reports. In the third year, we also provided a grading rubric to one of the two classes to see if that would improve their use of figures; we also assessed the students' quantitative literacy skills to see whether low QL skills might underlie their poor knowhow about graphs.

For the Polar Bear Module implemented in the Calculus I course, students were assigned short readings as an introduction on systems thinking, complex problems, and panarchy (Hamilton et al. 2013). The students were taught how to use Microsoft Excel to derive a best-fit curve from data. Later in the course they had to use their curve-fitting skills to model and interpret global average temperature and two years of data on the extent of Arctic sea ice. Once the students had their best-fit curves, they used their calculus knowhow to analyze the curves. They were then tasked with writing a technical report about their findings.

\footnotetext{
${ }^{4}$ http://physics.ithaca.edu/ msep/Materials-For-All/MSEP-Technical-Report-WritingInstructions.pdf. http://physics.ithaca.edu/ msep/Materials-For-All/MSEP-General-Student-RubricTechReport.pdf. http://physics.ithaca.edu/ msep/Materials-For-All/MSEP-General-Instructor-RubricTechReport.xls. All password protected. See preceding footnote.
} 
The figures found in the results sections of the students' technical reports were evaluated based on our expectations of what proper graphs should include. We expected the graphs to have the following: (i) labeled $x$ and $y$ axes, (ii) a label on the figure itself (e.g. "Figure 1"), (iii) a descriptive caption identifying and explaining the figure, (iv) rounded-off significant figures in the equations of lines appearing on the graphs, and (v) a connection between the graph/figure and its real-world implications in the text, either in the discussion or results section. These features were considered to be the components of an acceptable graph. Presence/absence data were collected for each category (i-v) on each report. From counts of these data, we determined percentages of category inclusion for each class section and year.

Next, we evaluated the discussion section of each report using a three-level rubric created for the project. The discussion section was important to us because of its dependence upon the data, and thus the figures. There were explicit requirements for the discussion section in the guidelines document (Appendix A for the first year; Appendix B for the second year). Students were expected to integrate their discussions with the figures in their papers. The scoring rubric designed for our project, presented in Figure 1, was crafted so that if followed, students would receive a minimum of 1 point. This score would indicate that they had mentioned the most important points in their papers while expressing some understanding of their graphs. In order to receive a 2-point score, a student had to have addressed and then expanded upon each point identified in the guidelines. Though the class from the first year was not provided with the guidelines sheet, the same grading scale was used with that year's discussion sections.

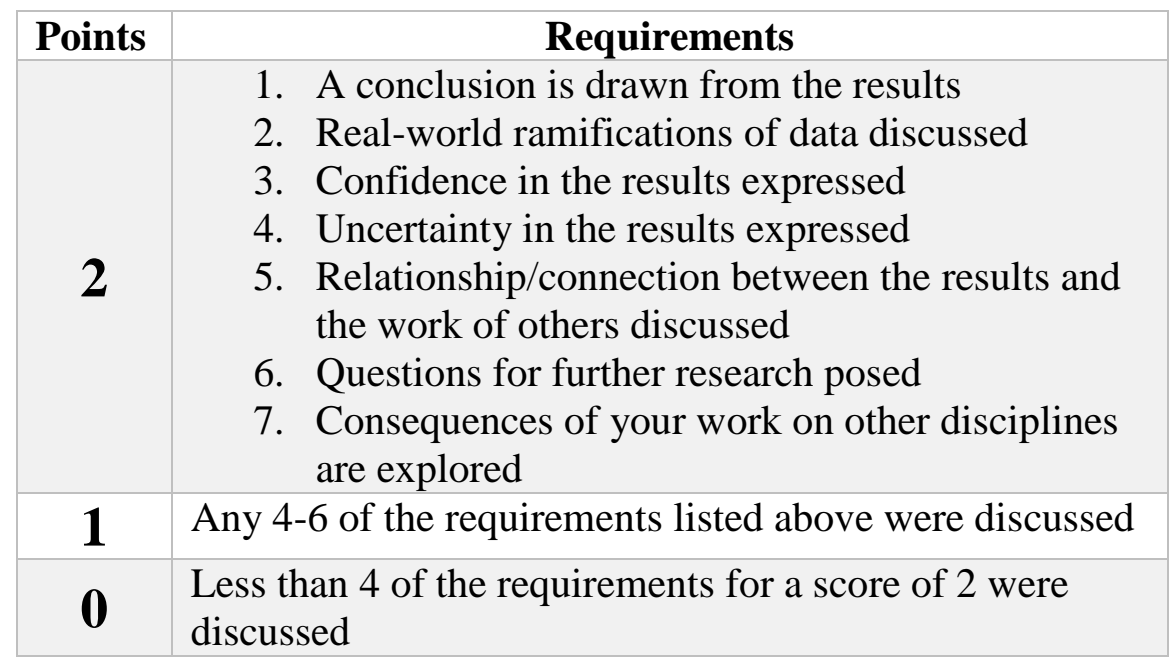

Figure 1. Rubric for scoring the discussion section. 
By the time of the last year of the study, we were convinced it would be worthwhile to test the ability of the students to read and interpret figures. If their graphing struggles were rooted in their failure to comprehend graphs and figures, then further work would be directed toward that issue. We decided to explore the possibility of a general QL deficiency amongst our students by adapting a previously published QL instrument. Our questionnaire (Appendix C) was based on a QL assessment vehicle developed at Michigan State University (Sikorskii et al. 2011) as part of a campus-wide QL initiative at that institution. Our questionnaire consisted of six questions - one from the basic form of the MSU assessment and five from the advanced form. We used it for pre-course and postcourse QL assessment of the Calculus 1 class in the third year of the study.

\section{Data and Analysis}

\section{Year One}

Due to the large size of the Calculus 1 class the first year of the study, those students were allowed to organize themselves into fifteen groups of three. Each group handed in its own report. All fifteen reports contained graphs in their results section, but only three designated their graph with a specific label (e.g., "Figure $1 ")$. Nine groups of students referred to their figure in their discussions. Three groups added descriptive captions to their figures. Five groups labeled their $x$ and $y$-axes and three of those five had included the caption. Eight other groups placed a title on their graph without adding a caption. In addition to the two groups who referenced their figure by mentioning its specific name in the text, seven groups referenced their graph with statements such as "the figure below," "the graph above,” or “the graph.” These results are listed in Table 1.

Table 1.

Year One Data - 15 Total Reports

\begin{tabular}{lcc}
\hline & \# of Reports & \% of Reports \\
\hline Axes Labels With Units Included & 5 & $33 \%$ \\
Captions Included & 3 & $20 \%$ \\
Title Without a Caption Included & 8 & $53 \%$ \\
Figure Label Included & 3 & $20 \%$ \\
Referred to Figure in Text & 9 & $60 \%$ \\
\hline
\end{tabular}

The Titled Without Caption element was tracked because we noticed that the students who weren't including a caption tended to include the title. We thought this might indicate that students believed that was the proper way to label a graph (without a caption).

This activity identified that the students clearly struggled with graph formatting in their reports. That only three reports coupled captions to figures was concerning, since the absence of a caption leaves readers with a lack of important information about the overall goals of the paper. Students were not explaining 
why their figures are important. Although nine groups referred back to their figures in their discussions, six made no mention of them at all. Fewer than half of the reports labeled $x$ - and $y$-axes, and just two labeled the figure. The MSE team had assumed that students had learned how to include all these details on their graphs while they were in high school. The team, along with the professor of the calculus class, had expected all of the groups of students to include each component of the graphs. Furthermore, since these students worked in groups of three, we wondered how the absence of axes labels, figure captions, and labels could go unnoticed by all the group members. We were looking for a $90 \%$ inclusion rate, a percentage we arbitrarily picked, as we expected students to make accidental errors occasionally with their figures. The data suggested this assumption was certainly poor; however, as we expect excellence from our students, we chose to keep it at that high level for the remainder of the study.

Seven of the discussion sections scored a 2 and eight of them scored a 1 . Recall that in order to receive a 2, the students needed to have discussed the implications of their data in the context of the Arctic wildlife; stated their uncertainty in their results; referred back to their figure's data explicitly; and summarized their findings in a discussion section. Common elements missing from student reports that scored a 1 included, but were not limited to: mention of uncertainty in results, and discussion of connections between their results and the work of others. Uncertainty may have been a new concept for these young students (first-year students), but the lack of discussion concerning outside work defeated the purpose of the module.

\section{Year Two}

To answer some of the questions prompted by our findings from Year One, the same professor's class was observed a year later. He used the same module, but this time he gave the students a technical report-writing guidelines sheet that laid out explicitly what was expected of the figures. ${ }^{5}$

Table 2.

Year Two Data - 18 Total Reports

\begin{tabular}{lccc}
\hline & \# of Reports & \% of Reports & $\begin{array}{c}\text { \% Excluding Reports } \\
\text { Without Figures }\end{array}$ \\
\hline Axes Labels With Units Included & 10 & $56 \%$ & $63 \%$ \\
Captions Included & 7 & $39 \%$ & $44 \%$ \\
Title Without a Caption Included & 7 & $39 \%$ & $44 \%$ \\
Figure Label Included & 6 & $33 \%$ & $38 \%$ \\
Referred to Figure in Text & 13 & $72 \%$ & $81 \%$ \\
\hline
\end{tabular}

As a whole, these percentages indicate that the students did not have a collective understanding of the expectations that their professors had with regard to their graphing skills.

\footnotetext{
${ }^{5}$ See second paragraph under results in Appendix B.
} 
The number of students in the class of Year Two was smaller, which allowed for individual report assignments. Of the 18 reports submitted (Table 2), 16 included a graph in the results section. Of those sixteen reports, seven titled their graphs without adding captions, and seven included captions. Thirteen students labeled the $x$ - and $y$-axes, but just ten of those were labeled with correct units. Seven students gave specific names to their figures and referred to them in the discussion section of their paper. Six other students made quick mention of their figure or figures in the text without specifying which figure they were commenting on.

Overall, we saw a modest improvement in desired outcomes in Year Two over Year One, even when factoring in the two reports without figures in Year Two. Nonetheless, the same formatting areas that troubled the student groups in Year One were problem areas for the students in Year Two as well. We had thought that by having the professor hand out guidelines identifying the components of a well-constructed figure that the proportion of students who included axes labels, captions, and the like would have increased past our $90 \%$ assumption from the first year. To the students' credit, over half of them remembered to label their figures with correct units. Fewer than half of them, though, labeled, discussed in the text, or captioned their figures.

The discussion sections were again lacking in quality overall in the class of Year Two. Just five reports received a 2, and eleven received a 1 . We were especially surprised to see twice as many reports failing to include everything we expected because, unlike for Year One, the guidelines sheet for Year Two (Appendix B) contained a bulleted list of requirements for that section.

After two years of this continuing disappointment, we began to wonder if the experience was pointing to a more serious issue in the students' understanding of graphs. The students may not be forgetting to use the graphs properly; in fact, they may not know at a fundamental level how to use graphs properly. On the other hand, the calculus textbook they used labeled graphs and other figures properly. Were the students paying attention to the graphs there? Or, were they just skimming the text and disregarding figures? The students may not have recognized the important connections between figures and text. They may not realize that figures serve a purpose.

\section{Year Three}

The guidelines given to students in Year Three were identical to those given in Year Two. There were two sections taught by the MSE professor in Year Three: Section A (23 students) and Section B (22 students). Both sections were given the assignment for the students to write a technical report, but there was a difference between the two sections in the way the assignment was made. Section A was given the grading rubric while the students were working on their reports, 
and Section B was not. The intent was to provide the Section A students with a rubric that explicitly states that they will be graded on aspects of their use of figures. To check whether the students reviewed the rubric carefully, the rubric included an explicit statement that asked the students to include a sentence in their introduction that gave the name of the professor, the section of the class, and the course number. What happened? Only eight students actually included this statement - a result that leads us to question whether providing students with a rubric has any of the benefits that we had expected. In fact (and in keeping with our new-found suspicion), there were no significant differences between the two sections' work (Table 3). A two-proportion test was used to compare the two sections (not-equal alternative hypothesis) with $p$-values ranging from 0.30 to 0.92. Note that the category "Captions Included" was omitted from the hypothesis tests due to failed assumptions on successes and failures of at least 5 each.

Table 3.

Year Three Data by Section - 45 Total Reports

\begin{tabular}{|c|c|c|c|c|}
\hline & \multicolumn{2}{|c|}{ Section A (23 Students) } & \multicolumn{2}{|c|}{$\underline{\text { Section B (22 Students) }}$} \\
\hline & \# of Students & $\%$ of Students & \# of Students & $\%$ of Students \\
\hline Axes Labels With Units Included & 8 & $35 \%$ & 12 & $55 \%$ \\
\hline Captions Included & 1 & $4 \%$ & 3 & $14 \%$ \\
\hline Title Without a Caption Included & 13 & $57 \%$ & 12 & $55 \%$ \\
\hline Figure Label Included & 7 & $30 \%$ & 7 & $32 \%$ \\
\hline Referred to Figure in Text & 17 & $74 \%$ & 14 & $64 \%$ \\
\hline
\end{tabular}

Of the 45 technical reports handed in by students, 39 of them included a graph (Tables 3 and 4). A total of 20 students labeled their $x$ - and $y$-axes; four added a caption to their figures; 25 titled their graph; 14 labeled their graph, and 31 referred to it in the text (Table 4).

Table 4

Year Three Data - 45 Total Reports

\begin{tabular}{lccc}
\hline & \# of Reports & \% of Reports & $\begin{array}{c}\text { \% Excluding Reports } \\
\text { Without Figures }\end{array}$ \\
\hline Axes Labels With Units Included & 20 & $44 \%$ & $51 \%$ \\
Captions Included & 4 & $9 \%$ & $10 \%$ \\
Title Without a Caption Included & 25 & $56 \%$ & $64 \%$ \\
Figure Label Included & 14 & $31 \%$ & $36 \%$ \\
Referred to Figure in Text & 31 & $69 \%$ & $79 \%$ \\
\hline
\end{tabular}

Also of interest: eight out of Section A's 23 students included the mandatory statement in their introductions, and none of the Section B students did so. This 
result may suggest that the Section A students did not share the grading rubric with the Section B students.

As in Year One and Year Two, the majority of students referred to their figures in their reports in Year Three. There were no distinct patterns in the data with year-to-year comparisons. Most of the students used the numbers they obtained from their calculations to support their predictions for future average temperatures and sea ice extent. Many who made those predictions made reference to the behavior of the graph for their support, but we had hoped that all of the students would have done so. Figures serve as visual representations of the data from which they are crafted, and they can be just as effective, if not more effective, than equations and numbers at convincing readers.

Although the students were often correct in their predictions, the Year Three students still struggled with the graph formatting (Table 5). Recall that in moving from year to year, we introduced interventions to increase the occurrence of proper use of figures. In Year Two, we added explicit instructions, and in Year Three, one of the two sections even received the rubric the professor used to grade the reports. A two-sample proportion test was used to compare the five items of graph literacy listed in the tables between Year One and Year Two; between Year One and each section of Year Three; and between Year One and combined Year Three, with a not-equal alternative. In all instances, we failed to reject the null hypothesis with $p$-values ranging from 0.202 to 0.942 . Note that the items of "caption included" and "figure label included" both failed the assumption of at least 5 successes and 5 failures for each group for both Year One vs. Year Two and Year One vs. Year Three.

Table 5

Comparison of Reports by Year - 78 Total Reports

\begin{tabular}{lccc}
\hline & $\begin{array}{c}\text { \% of Reports } \\
\text { Year 1 }\end{array}$ & $\begin{array}{c}\text { \% of Reports } \\
\text { Year 2 }\end{array}$ & $\begin{array}{c}\text { \% of Reports } \\
\text { Year 3 }\end{array}$ \\
\hline Axes Labels With Units Included & $33 \%$ & $63 \%$ & $51 \%$ \\
\hline Captions Included & $20 \%$ & $44 \%$ & $10 \%$ \\
Title Without a Caption Included & $53 \%$ & $44 \%$ & $64 \%$ \\
\hline Figure Label Included & $20 \%$ & $38 \%$ & $36 \%$ \\
Referred to Figure in Text & $60 \%$ & $81 \%$ & $79 \%$ \\
\hline Included a Figure & $100 \%$ & $89 \%$ & $87 \%$ \\
\hline
\end{tabular}

Our evidence supports the conclusion that students do not know how to properly incorporate their figures in their reports. The fact could be that they lacked the necessary understanding of Microsoft Excel needed to add labels and axes names. However, asking the professor how to include those labels or even performing a quick search on the Internet could have provided them with that understanding. Assuming the students care about their grades or about completing 
high-quality work, our finding implies that a significant proportion of the students do not recognize the importance of labeling axes. We note, however, that there are many variables, both inside and outside of the classroom, which can and do affect student performance.

The discussion scores for Year Three were similar to that of Year Two. There were 14 reports that received a score of 2 points; 27 received a 1; and five received zero. It was concerning to see five students submit papers with abysmal discussion sections, some of which were 1-3 sentences long in total. Once again, the number of students who received a 1 was twice the number that received a 2 . Even though required elements for the discussion were laid out explicitly for them in their writing instructions sheet, students were still missing elements.

The percentages of students referencing their figures in their test increased with each year, so there is evidence that the guidelines may have made a positive difference. However, 23 papers did not even have their discussion sections labeled in their reports. Labeling sections was not an explicit requirement, but it is standard practice to define separate sections within a technical report.

\section{Quantitative Literacy Questionnaire Analysis}

By Year Three, we were concerned that the errors in students' figures might be due to deficiencies in Quantitative Literacy and sought to check their QL understanding before taking the class. As noted in Methods, we used a QL questionnaire adapted from a Michigan State University resource published in Numeracy (Sikorskii et al., 2011). The six-question, multiple-choice pre-test and post-test data presented in Figure 2 show that, in general, the students did not have difficulties reading figures and answering questions about them.

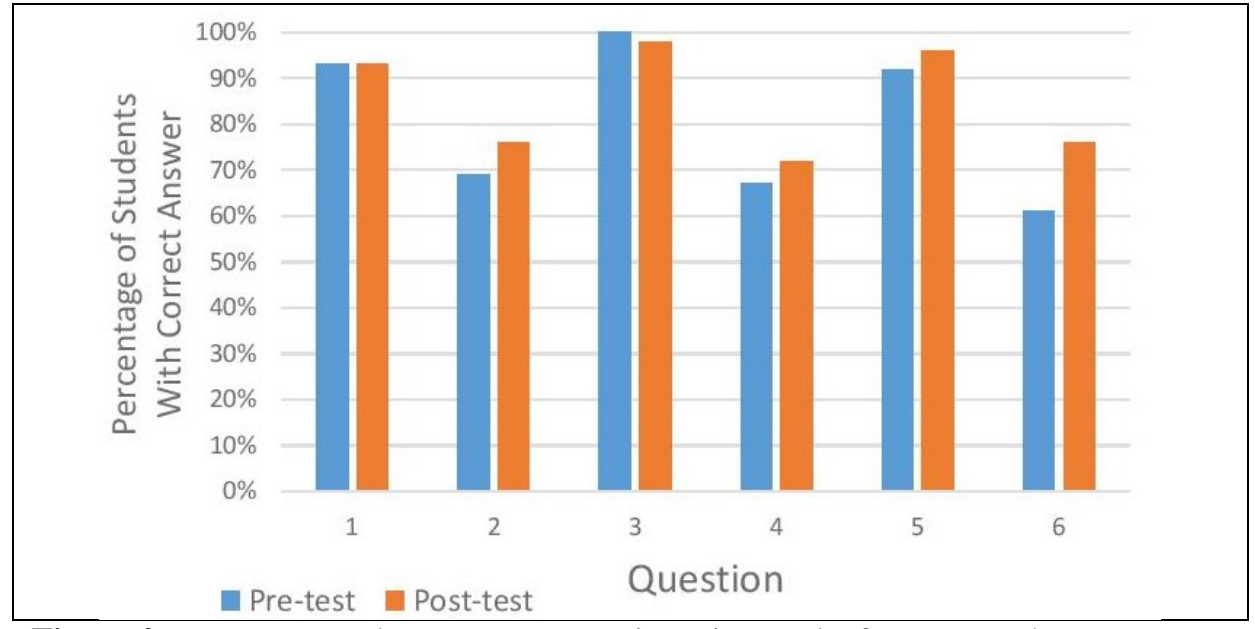

Figure 2. Pre-course and post-course questionnaire results from Year Three. The students apparently did not have a serious QL deficiency before starting the class. The $n$-value is 45 . 
All six questions for Figure 2 can be found in Appendix C. Each question was answered correctly by at least 60\% of the participants. Questions 1, 3, and 5 were each answered correctly by over $90 \%$ of participants on both tests. Question 1 contained a pie chart with three slices and asked the students to choose a true statement found by adding up the percentages written the slices. Question 3 had students examine sets of data on a bar graph and choose the correct answer based on the relationships shown by the graph. Question 5 contained a scatter plot with a trend line meant to show the correlation between breast cancer and the death rates of women in different decades; the question asked the students to predict the future death rate from the trend. Question 2 contained a table but not a graph; we included this question to see if a change in data presentation affected how easily a student interpreted the data - it seemed to have no significant effect. Questions 4 and 6 did concern graphs, and by the end of the course over $70 \%$ of the students showed that they could interpret those graphs to answer the questions. We conclude that students did not have QL deficiencies in interpreting graphs; deficient QL, as tested by our assessment instrument, was not the source of their issues with including figures in their report.

\section{Summary and Conclusion}

Many of the first-year students struggled to include proper figures in the technical reports that they wrote for their Calculus I class. When we first assigned technical reports to students, we expected that most of the figures found in the reports would contain all of the components we were looking for: axes labels (with proper units), captions, figure labels, and references to the figures in the text. After analyzing data from three years of assigning reports, with increasing guidance for students, we found that this expectation was much too high. Our guidelines did little to help. It could be the students disregarded the guidelines altogether, or it could be that they skimmed the guidelines and missed our suggestions for what should be included in their figures, but, whatever, it is clear that the proper use of figures is not a habit.

We consider the fact that students do not use figures correctly to be a serious issue. Figures are a crucial component of expressing information and an integral part of exposition, especially about technical material. It is clear that in writing reports students do not see this important connection, and so we question whether students make the connection between text and figures when reading technical reports. We expect they do not.

Our students no doubt have the aptitude to learn best practices regarding the incorporation of figures. Some of the common issues they demonstrated undoubtedly trace back to their lack of experience writing this type of paper and an absence of explicit classroom discussion or activities to identify exemplars. 
The results obtained from our study indicate that many of the students do not recognize the importance of including labeled figures in their papers, nor do they effectively use them to support their own conclusions. Both middle and highschool math courses instruct students to label $x$ - and $y$-axes, but how many of those courses teach students to properly caption figures? When, if ever, do students learn to use figures appropriately? At what point in their secondary schooling are they taught how to analyze figures in their reading? Lack of education on the use of figures is why explicit instruction in the first-year college classroom could be so helpful - we could set the student standard for years to come.

There is clearly more research to be done in understanding how students connect figures and text in their reading and writing, but empowering all students with quantitative literacy skills should be a goal STEM professors strive toward when teaching introductory classes.

\section{Acknowledgments}

We would like to thank the MSE Project Team and the calculus students for supporting our research. Thanks to Alla Sikorskii for allowing us to reprint portions of the Michigan State University Quantitative Literacy test. This research was funded in part by the National Science Foundation grant DUE\#0837721 (see footnote 1).

\section{References}

Allen, I. E. and C. A. Seaman. 2007. "Likert Scales and Data Analyses.” Quality Progress 40: 64-65.

Ausubel, D. P. 1960. "The Use of Advance Organizers in the Learning and Retention of Meaningful Verbal Material.” Journal of Educational Psychology 51(5): 267-272. https://doi.org/10.1037/h0046669.

Corkill, A. J. 1992. “Advance Organizers: Facilitators of Recall.” Educational Psychology Review 4(1): 33-67. https://doi.org/10.1007/BF01322394.

Erkan, A., T. Pfaff, J. Hamilton, and M. Rogers. 2012. "Sustainability Themed Problem Solving in Data Structures and Algorithms.” In SIGCSE '12: Proceedings of the 43rd SIGCSE Technical Symposium on Computer Science Education 9-14. https://doi.org/10.1145/2157136.2157146.

Erkan, A., J. Hamilton, T. Pfaff, and M. Rogers. 2010. "Use of Satellite Imagery in Multidisciplinary Projects.” In SIGCSE '10: Proceedings of the 41st SIGCSE technical symposium on Computer Science education 32-36. https://doi.org/10.1145/1734263.1734275.

Estry, D. W. and J. Ferrini-Mundy. 2005. Quantitative Literacy Task Force Final Report and Recommendations, Michigan State University. 
http://acadgov.msu.edu/sites/default/files/content/QLFinalReport-1.pdf Retrieved March 1, 245-360.

Hamilton, J., M. Rogers, T. Pfaff, and A. Erkan. 2010. "Multidisciplinary Collaborations in the Traditional Classroom: Wrestling with Global Climate Change to Improve Science Education.” Transformations: The Journal of Inclusive Scholarship and Pedagogy. 21(1): 89-98. http://www.jstor.org/stable/10.5325/trajincschped.21.1.0089.

Jonsson, A. and G. Svingby. 2007. "The Use of Scoring Rubrics: Reliability, Validity and Educational Consequences.” Educational Research Review 2: 130-144. https://doi.org/10.1016/j.edurev.2007.05.002.

Likert, R. 1932. "A Technique for the Measurement of Attitudes.” Archives of Psychology, 22 (140), 55 pp. Available at: http://www.voteview.com/pdf/Likert_1932.pdf.

Mayer, R. E. and R. Clark. 2003. "The Promise of Educational Psychology (vol ii): Teaching for Meaningful Learning.” Performance Improvement 42: 4143. https://doi.org/10.1002/pfi.4930420410.

Panadero, E. and A. Jonsson. 2013. "The Use of Scoring Rubrics for Formative Assessment Purposes Revisited: A Review.” Educational Research Review 9: 129-144. https://doi.org/10.1016/j.edurev.2013.01.002.

Pfaff, T., A. Erkan, J. Hamilton, M. Rogers. 2011. "Multidisciplinary Engagement of Calculus Students in Climate Issues." Sencer: Science Education and Civic Engagement-An International Journal 3(1). Available at http://sencer.net/wp-content/uploads/2016/12/seceij_winter_2010.pdf.

Pfaff, T., M. Rogers, A, Erkan, and J, Hamilton. 2011. "Go Figure: Calculus Students use of Figures and Graphs in Technical Report Writing.” Numeracy 4(1): Article 6. https://doi.org/10.5038/1936-4660.4.1.6.

Rogers, M., T. Pfaff, J. Hamilton, and A. Erkan. 2013. “Incorporating Sustainability and 21st Century Problem Solving into Physics Courses." The Physics Teacher 51: 372. https://doi.org/10.1119/1.4818380.

Rogers, M., T. Pfaff, J. Hamilton, and A. Erkan. 2015. "Using Sustainability Themes and Multidisciplinary Approaches to Enhance STEM Education." International Journal of Sustainability in Higher Education 16(4): 523-536. https://doi.org/10.1108/IJSHE-02-2013-0018.

Sikorskii, Alla; V. Melfi, D. Gilliland, J. Kaplan, and S. Ahn. 2011. "Quantitative Literacy at Michigan State University, 1: Development and Initial Evaluation of the Assessment." Numeracy 4 (2): Article 5. https://doi.org/10.5038/1936-4660.4.2.5. 


\section{Appendix A: Technical report guidelines given to students in the first year.}

These guidelines were handed out to students in the Calculus I class in year one. Notice the emphasis placed on including a figure in the results section.

Technical Report

MATH-111

Directions: Your group will write a technical report on the work done analyzing the average global temperature data. The report must be submitted to me by email in pdf format. Full names of each group member must be on the report. Your report will be sent to students in other classes on campus as they will attempt to answer some of our questions. The reports will also be posted so that other class members may view the report. The sections of the report are defined below.

Introduction: The introduction is where you describe why anyone should read your report. What is the motivation? What is the problem? What is the importance? The idea is to provide context, state clearly the nature of your work, and your approach.

Methods: In this section you should describe what you did and how you did it. It is important to include a discussion or diagrams or both of approaches or equipment or software used. You should clearly discuss the techniques you applied.

Results: You must present the results of your work in this section. Common presentation methods are tables and figures where figures can contain graphs, pictures, photographs, or other images. Most people who read a technical report look at the figures in the report first, as such, your figures should completely describe your results. Be wary of too few or too many figures. Figures are perhaps the most important part of the whole technical report, and many people create the figures first and write the paper around the figures.

Discussion: This section is where you discuss the ramifications of your results and your confidence in those results. You should include a discussion of uncertainties. This is the section where all of the elements should be tied together with a compelling narrative. This where you explain IN ENGLISH WORDS what your results show and what you have determined. In other words, why should anyone care about your work?

Questions: This section is where you indicate questions generated by your work that need answering. You do not need to answer these questions because that will be the task of students in another class with the required expertise 


\title{
Appendix B: Technical report guidelines given to students in the second year.
}

\author{
Technical Report Writing Instructions
}

\section{- Introduction:}

This is the section where you describe why anyone (both inside and outside your particular field) should read your report. What is your motivation? What is the problem? What is the importance of the problem? The idea is to provide context, state clearly the nature of your work and approach.

\section{- Methods:}

This is the section where you describe what you did and how you did it. It is important to include a discussion or diagrams (or both) of approaches/equipment/software used. You should clearly discuss the techniques you applied.

\section{- Results:}

This is the section where you present the results of your work. Common presentation methods are tables and figures where figures can contain graphs, pictures, photographs, or other images. Figures are perhaps the most important part of the whole technical report; many people create the figures first and write the paper around the figures. Similarly, most people who read a technical report look at the figures first; consequently, your figures should describe your results completely. However, you should also be wary of too few or too many figures.

When you include graphs/figures/tables in your results, please make sure that they are labeled and captioned properly. In addition, each graph/figure/table must be referenced from the main text; a graph/figure/table that is not explicitly referenced from the main text should be taken out.

\section{- Discussion:}

This is the section where, in a compelling narrative form (without much dependence on discipline specific jargon), you discuss the following issues:

- The conclusions drawn from your results.

- The real-world ramifications of your results.

- Your confidence in your results.

- The extent of uncertainties (if present) in your results.

- The relations/connections between your results and others' work.

- The consequence of your results on other disciplines.

You can/should should also address new questions that are generated by your work:

- What should be done next?

- What should be societies' response?

- What do you need to know in order to do a better job in answering your original question?

- Who might have the expertise or research tools to answer the new questions you have generated?

These could be left open-ended since they could/will be addressed by students in another class with the required expertise.

\section{- Citations:}

Include the references you used (if any). 


\section{Appendix C: Quantitative literacy assessment for the Year 3 classes.}

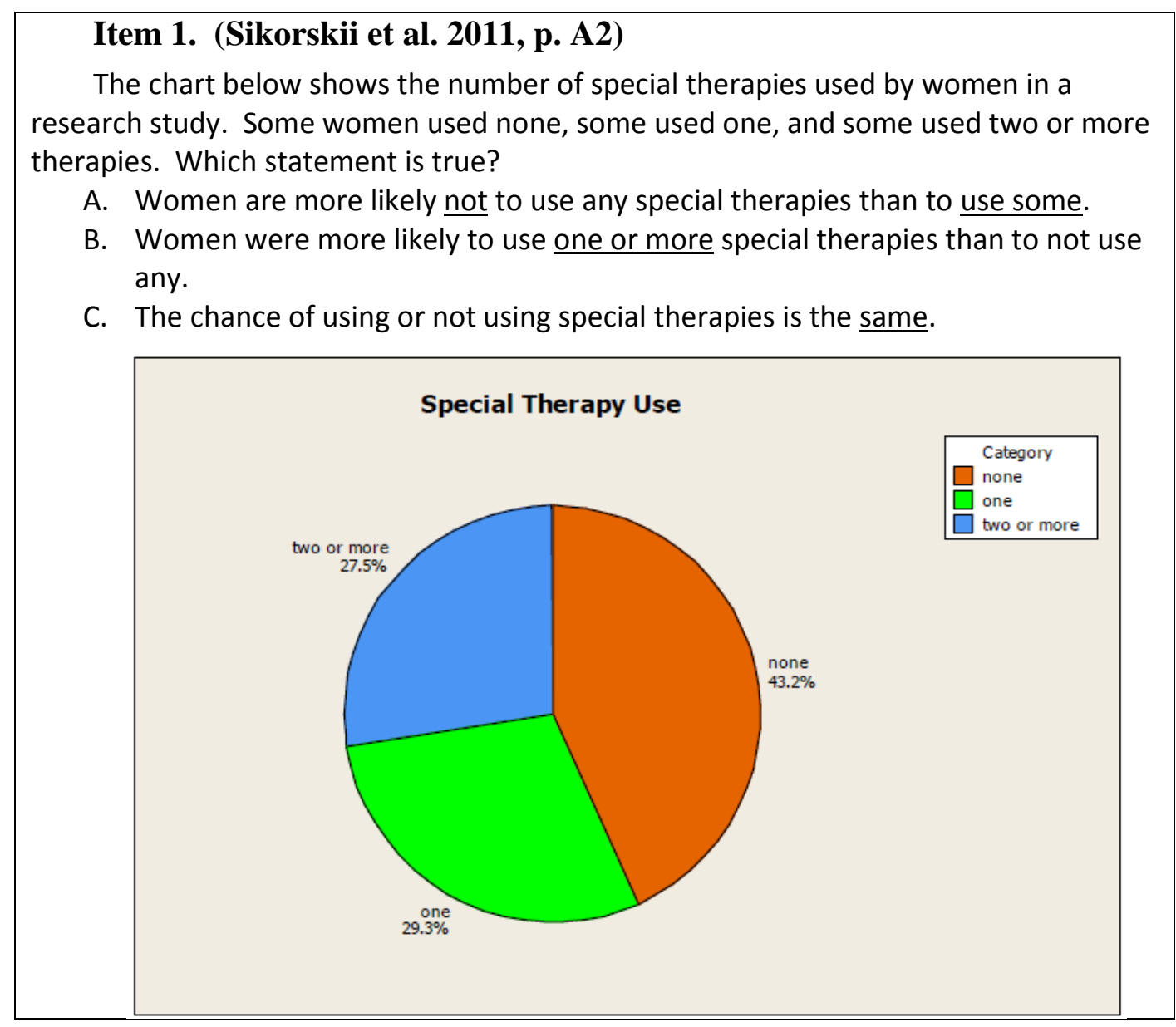

\section{Item 2. (Sikorskii et al. 2011, p. A5)}

College students were asked whether they had ever engaged in binge drinking. Their answers, classified by gender, are in the table below. What percent of those who reported engaging in binge drinking were male?
A. $61 \%$
B. $46 \%$
C. $20 \%$
D. $86 \%$
E. $154 \%$

\begin{tabular}{|c|c|c|}
\hline & \multicolumn{2}{|c|}{ Binge Drinking } \\
\hline Gender & Yes & No \\
\hline Male & 43 & 50 \\
\hline Female & 28 & 92 \\
\hline
\end{tabular}




\section{Item 3. (Sikorskii et al. 2011, p. A12)}

The chart below gives the number of prostate cancer cases and deaths from it, per 100,000 males, for 1975-2004. In 1990-1994, compared to 1985-1989, the number of cases per 100,000 (pick the true statement):

A. Increased, but the number of deaths per 100,000 decreased.

B. Decreased, but the number of deaths per 100,000 increased.

C. Increased, but the number of deaths per 100,000 remained the same.

D. Remained the same, but the number of deaths per 100,000 decreased.

E. Remained the same, and the number of deaths per 100,000 remained the same.

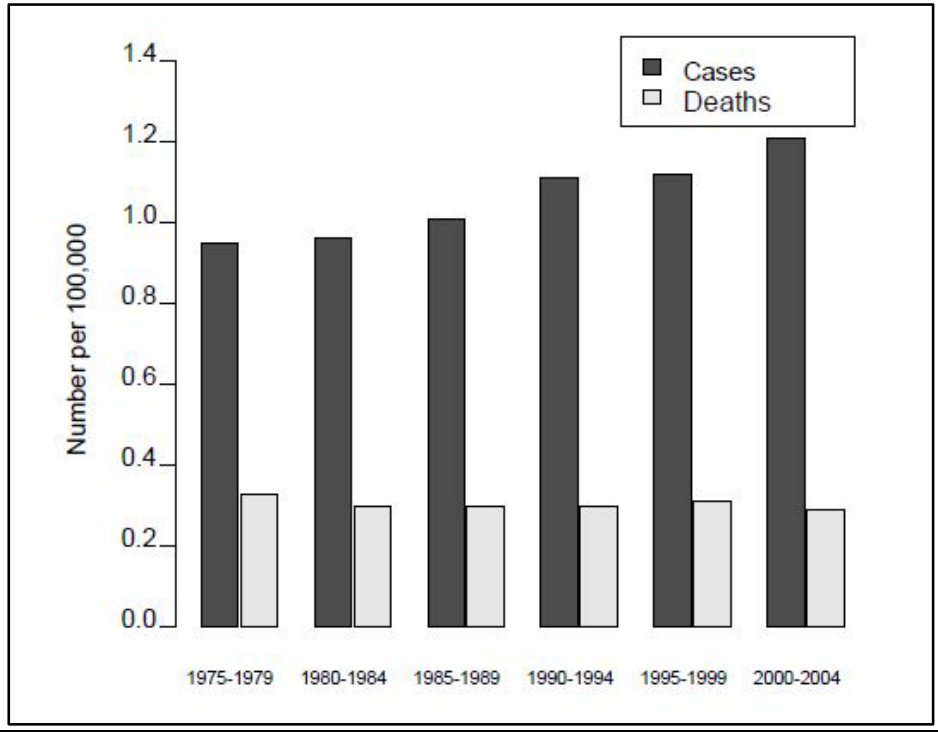

\section{Item 4. (Sikorskii et al. 2011, p. A4)}

At an ice cream factory, a cone, like the one pictured here, is being filled by liquid ice cream at a constant rate, until it is full. Which of the following graphs is the best representation of the relationship between the height of the ice cream and the amount of time?
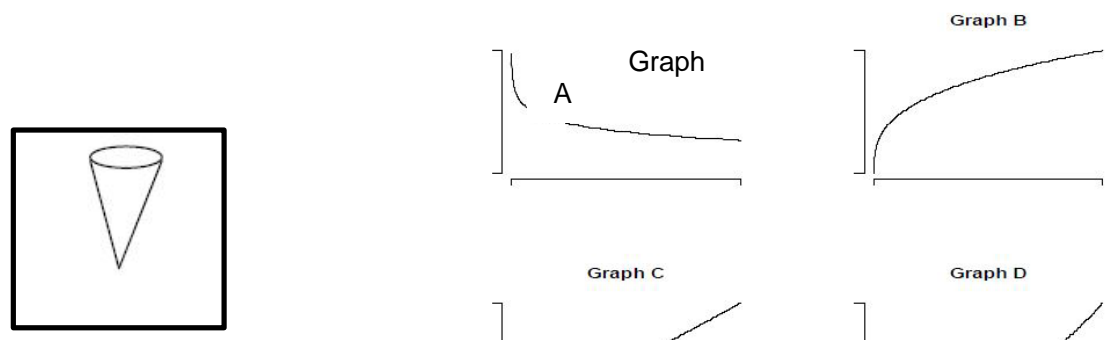

Graph C

Graph D
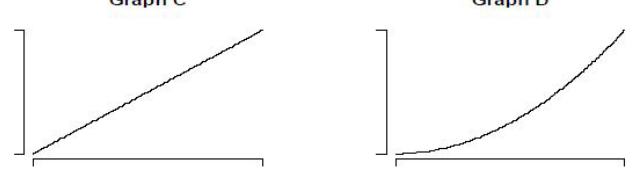


\section{Items 5 and 6. (Sikorskii et al., 2011, p. A18)}

The chart below shows the death rate per 100,000 women from breast cancer for each year since 1976 . The best fit line is drawn on the figure.

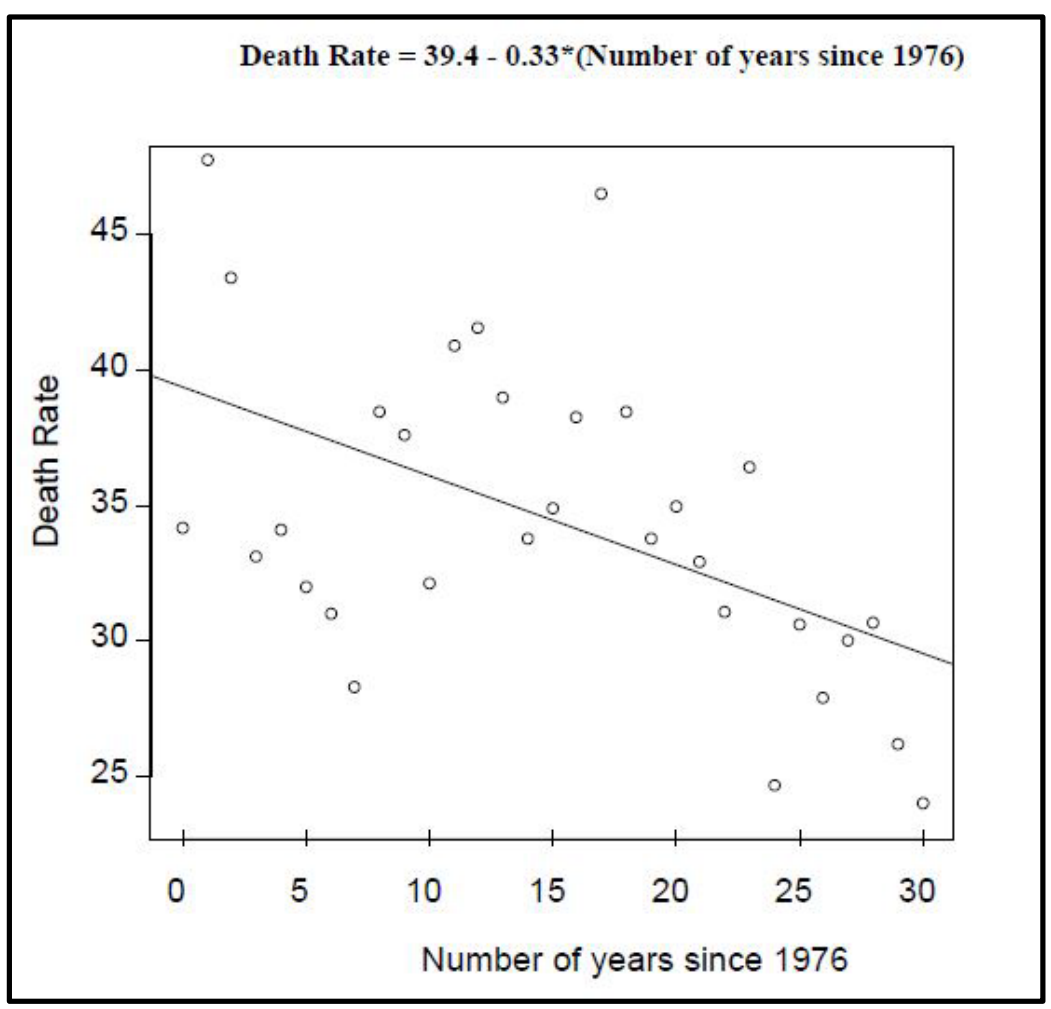

If the trend continues, what death rate in 2010 can be predicted from this line?
A. 39
B. 28
C. 1
D. 11
E. 663

Based on the line Death Rate $=39.4-0.33 *$ (Number of years since 1976) in the chart above, about how many years will it take for the deaths per 100,000 to go down by 1 ?
A. 0.33
B. 39.4
C. 39.07
D. 1
E. 3 